
3 Research Square
Preprints are preliminary reports that have not undergone peer review.
They should not be considered conclusive, used to inform clinical practice, or referenced by the media as validated information.

\title{
Impact of COVID-19 on ESG risk, stock returns, and firm performance: Evidence from Japanese firms
}

Miho Murashima ( $\nabla$ murashima@rikkyo.ac.jp)

Rikkyo University: Rikkyo Daigaku https://orcid.org/0000-0001-6807-0812

\section{Research Article}

Keywords: ESG performance, stock returns, firm performance, COVID-19, Japan

Posted Date: February 25th, 2022

DOI: https://doi.org/10.21203/rs.3.rs-1183641/v1

License: @ (i) This work is licensed under a Creative Commons Attribution 4.0 International License. Read Full License 


\section{Abstract}

This study examines the impact of environmental, social, and governance (ESG) performance on stock returns and firm performance with the interaction effect of COVID-19, focusing on businesses with low ESG performance. We applied difference-in-differences regression to evaluate how these indicators changed after COVID-19, studying 7,868 samples of 882 firms from June 2016 to March 2021. Our analysis revealed that the impact of ESG risk on long-term firm valuation, represented by Tobin's Q, shifted in the years after COVID-19. We also found that there was a change in the magnitude of ESG risk, especially the impact of high ESG risk on sales as well as return on equity, before and after the COVID-19 pandemic. In the post-COVID-19 climate, our study suggests that managers should place greater emphasis on ESG efforts, which allow businesses to keep consumers and investors engaged and financially secure, even during unanticipated external shocks. More proactive sharing of information on a company's ESG operations will be essential, particularly for consumers and investors who may be influenced by the signaling effects of ESG ratings.

\section{Introduction}

This study investigated the change in the relationship between a firm's environmental, social, and governance (ESG) risk, stock returns, and performance before and after the COVID-19 pandemic in 2020. The COVID-19 outbreak has dealt a huge socio-economic shock worldwide, and made a profound impact on people's sense of values (He and Harris 2020). Moreover, the ESG performance of companies has started affecting the decisions of investors world over; the expectation being that higher ESG performance will increase corporate value and resilience (Friede et al. 2015). Although research in this field is on the rise and previous studies have analyzed the impact of high ESG rating, their findings were inconclusive (Friede et al. 2015; Revelli and Viviani 2015; Broadstock et al. 2021). Given the increase in the number of bankruptcies due to COVID-19 (Teikoku Databank 2021), we should focus on the risks associated with alow ESG rating. Therefore, this study contributes to the academic literature by revealing the changes in the risk of a low ESG.

ESG activities are expected to have several impacts on businesses. A high ESG rating indicates the compatibility of the company's strategy with social discipline, which can be expected to be sustainable (Suchman 1995; Lai et al. 2016). This provides stakeholders, including customers and investors, with a sense of security, while meeting their willingness to contribute to society (Galbreath 2013; Sison et al. 2019). Therefore, improving a company's ESG activities is known to increase corporate value. Friede et al. (2015), in their comprehensive review of 2,200 academic studies on this subject, found that a majority of the studies reported a positive relationship between ESG and corporate financial performance. Moreover, emerging research suggests that high-sustainability companies have reduced downside risks and are more robust during difficult times. While Hoepner et al. (2016) showed that shareholder involvement in ESG concerns reduces companies' downside risks, as assessed by the lower partial moment and value at risk, Ortas et al. (2014) found that increased resilience to severe shocks may be the result of a firm's pro-social efforts.

A firm's ability to maintain value and performance is easier to observe during social and economic shocks. Simultaneously, the greater the shock and risk to life, the more likely that people, including customers and investors, will change their values (Loewenstein 2000; Gualtieri et al. 2019), such as firms' ESG performance. The unusual conditions of COVID-19 provide an unrivaled opportunity to consider whether investors see ESG performance as a predictor of future stock performance and/or risk reduction (Broadstock et al. 2021). Similarly, Albuquerque et al. (2020) stated that this crisis offers an unprecedented opportunity to put environmental and social policy ideas to test.

Emerging studies have analyzed the relationship between ESG, stock returns, and corporate performance during COVID-19. Broadstock et al. (2021) investigated the role of ESG performance during the global financial crisis triggered by the COVID-19 pandemic. Their study had three major findings: 1) highESG portfolios outperform low-ESG portfolios; 2) ESG performance minimizes financial risk during great recession; and 3) the importance of ESG performance increases during crises. Moreover, Kanamura (2021) used high-yield bond exchange-traded funds (ETFs) to examine the impact of ESG factors on financial products; their study revealed the hedging effects of ESG performance on the market risk of typical high-yield bond ETF prices during COVID-19. By employing a difference-in-difference analysis, Albuquerque et al. (2020) also demonstrated that companies with higher ESG scores had substantially better returns, reduced return volatility, and greater operational profit margins during COVID-19. However, their results were inconclusive. Demers et al. (2021) stated that after controlling for industrial group, market-based risk measures, accounting-based measures of performance, financial position, and intangibles investments, ESG did not have a significant impact on returns during the COVID-19 period, implying that ESG did not "immunize" stocks during the COVID-19 crisis. In addition, Folger-Laronde et al. (2020) analyzed the differences and relationship between ETF financial returns and their eco-fund ratings during COVID-19, and found that higher sustainability standards for ETFs did not protect investments against financial losses during severe market downturns. Bae et al. (2021) also concluded that corporate social responsibility (CSR) activities conducted before the crisis were unable to protect shareholders' wealth from the negative impacts of COVID-19. Moreover, they suggest that companies' CSR approaches may be disconnected from their real activities. While many studies have analyzed the benefits of good ESG performance, few focus on the risks of bad ESG performance during external shocks.

Furthermore, despite the fact that Japan is the world's third-largest source of sustainable investment after Europe and the United States (Global Sustainable Investment Alliance 2018), there is little research on the Japanese market. Although Takahashi and Yamada (2021) examined the variables influencing the stock prices of Japanese companies during the COVID-19 crisis, they did not identify a significant relationship between ESG scores and abnormal returns.

As noted above, there is no consensus on the impact of COVID-19 on the relationship between corporate ESG performance, stock returns, and performance, with few studies focusing on the risk side of ESG and the Japanese market. Therefore, in this study, we analyzed the changes in the relationship between ESG performance, stock returns, and firm performance before and after COVID-19 in Japan, with a particular focus on companies with poor ESG performance. For the dataset of 7,868 samples from 882 companies from June 2016 to March 2021, we used difference-in-differences regression to assess the impact of the indicators of ESG risk, COVID-19, stock returns, and firm performance. Moreover, interpreting the results from the unique perspective of the Japanese market makes this study more original. The results will not only provide important insights for Japan, but also for other countries at a similar stage of ESG deployment, including those in East Asia. 
This study is expected to provide greater insights by revealing the change in the impact of COVID-19 on the relationship between poor ESG performance and resilience by focusing on "ESG risk," despite the paucity of related studies. Using the difference-in-differences method, we successfully captured the beforeafter impact by introducing the intersection term of the ESG risk index and the post-COVID-19 dummy variable. In the data collection process, we were able to enhance the reliability of this study by adopting the "Sustainalytics ESG Risk Rankings," an index that focuses on ESG-related risks. In addition, by using the most recent data possible, we conducted the analysis after COVID-19, for which there are still few studies.

This study provides important suggestions for managers. In the post-COVID-19 climate, our study indicates that managers should place a higher emphasis on ESG efforts. Companies can earn higher stock returns and firm performance as a result of this, keeping consumers and investors engaged and financially stable even when faced with unanticipated external shocks. In particular, companies may wish to focus on issues like "access to essential services such as healthcare," "generic professional ethics such as taxes and accounting," "community relations," and "emissions, effluents, and trash," which will need company-wide planning and action. Furthermore, greater proactive sharing of information on the company's ESG operations will be a key approach, particularly for consumers and investors who may be influenced by the signaling impacts of ESG ratings.

The remainder of this paper is organized as follows. Section 2 focuses on the theoretical background and hypotheses. Sections 3 and 4 discuss the data and research methodology, respectively. Section 5 provides the empirical results. Section 6 discusses the findings of this analysis. Section 7 concludes the paper, including the practical consequences and future research.

\section{Background And Hypotheses}

\subsection{ESG performance and stock returns}

The ESG performance of a firm also affects investor behavior. A company that is proactive about ESG will be considered trustworthy, with a stable management policy, by investors. For legitimacy and reputation benefits, as well as cost and risk reduction, investors reward companies that can react quickly using socially responsible operations (Carroll and Shabana 2010). In other words, companies can foster investor credibility through ESG activities, while preventing them from leaving when there are external shocks such as COVID-19, which indicate a fall in stock prices (Albuquerque et al. 2020). Adams and Abhayawansa (2021) also insisted on the importance of ESG disclosure for investing decisions. However, companies that are riskier in terms of ESG have weaker connections with investors, thus external shocks are more likely to lead to stock price crashes. Similarly, Shanaev and Ghimire (2021) showed that upgrading the ESG score leads to small positive returns, whereas downgrading substantially reduces returns.

\subsection{ESG performance and firm performance}

In this study, firm performance is represented by sales and financial stability, since these indicators measure a firm's ability to maintain stable sales while avoiding financial difficulties. In terms of sales, a company's ESG performance affects customer behavior. By proactively engaging in ESG activities, companies can improve their evaluation and image with customers, while increasing the volume of "fans." Thus, higher ESG performance results in an increase in loyal customer base and a reduction in the price elasticity of demand for their goods (Albuquerque et al. 2020). In fact, many companies are stepping up their ESG efforts using a "product differentiation strategy" (Albuquerque et al. 2019). However, if a company is perceived by its clients as having ESG risks, or as being "irresponsible," the credibility of the company will decline. When there is an external shock such as COVID-19, customers may immediately leave the company, leading to a decrease in sales. A company's ESG performance is also related to its financial stability. In addition to avoiding certain socially and ecologically unacceptable risks, sustainable and responsible policies can minimize corporate financial risks when a crisis occurs (Ortas et al. 2014) .

\subsection{Impact of COVID-19 on relationship between ESG risk, stock returns, and firm performance}

This study aimed to examine the relationship between a company's ESG risk, stock returns, and financial performance owing to the COVID-19 pandemic. In this section, we review earlier studies on the relevant themes.

Regarding stock returns, many studies have concluded that after an external shock, investor behavior becomes more risk-averse (Heaton and Lucas 2000; Kuhnen and Knutson 2011; Guiso et al. 2018; Wang and Young 2020). Ortmann et al. (2020) examined investors' responses to the COVID-19 outbreak using transaction-level trading data, and discovered that investors significantly reduced leverage. Rubbaniy et al. (2021) found a significant and positive correlation between the COVID-19 health fear index and ESG stock returns, implying that ESG equities possess "safe-haven" characteristics. By examining the relationship between ESG ratings and stock performance during the COVID-19 crisis, Engelhardt et al. (2021) and Yoo et al. (2021) showed that high ESG-rated European companies are linked with greater abnormal returns and reduced stock volatility. Díaz et al. (2021) also claimed that the COVID-19 outbreak has highlighted ESG investment, and that the ESG factor, in addition to Fama-French factors, explains a substantial portion of sector performance. Many other studies have demonstrated that active participation in social and environmental activities may be a signal for a credible company to invest in risk-averse situations (Jo and Na 2012; Durand et al. 2019; Saxton et al. 2019; Shanaev and Ghimire 2021). This implies that a business will be classified as high-risk if it has a negative effect on any of the CSR problems. Given the above, the first hypothesis is as follows.

\section{H1: A negative relationship between corporate ESG risk and stock returns is reinforced by the COVID-19 pandemic.}

Next, we discuss how external shocks alter consumer behavior, as an indicator of firm performance. Individuals' economic activities and preferences are influenced by emotions such as frustration, anxiety, and shame (Loewenstein 2000; Gualtieri et al. 2019). Consumer behavior after an external shock such as a crisis can be summed up by "Mindfulness Consumption." Mindfulness Consumption, introduced by Sheth et al. (2011) is "the guiding principle in this approach [, which] is premised on a consumer mindset of caring for self, for community, and for nature, that translates behaviorally into tempering the self- 
defeating excesses associated with acquisitive, repetitive, and aspirational consumption" (Sheth et al. 2011, pp. 21). Experiencing economic or natural threats that are beyond their control, people want something more "authentic" for a greater sense of social connection. According to a survey conducted by Euro RSCG Worldwide (2010) in France, the United States, and the United Kingdom, quality, which is defined as healthy, strong, sustainable, and responsible, takes precedence over price for the new consumer after crisis. Voinea and Filip (2011) also concluded that consumers have grown more responsible due to recession. Therefore, consumers tend to prefer socially meaningful products and firms after an external shock, such as COVID-19.

External shocks affect companies' business strategies. According to Nguyen et al. (2015), a strong governance policy reduces the interruption to businesses' financing and investment activities induced by bank credit supply shock. During the COVID-19 crisis, Jebran and Chen (2021) also emphasized the significance of good corporate governance, particularly independent risk management and institutional board independence, above other governance characteristics. This indicates that firms would choose a more risk-averse and conservative governance strategy, leading to high ESG performance in the presence of a major shock such as COVID-19. In other words, companies with poor ESG performance have insufficient financial strength even after shocks. The second hypothesis, based on the above theory, is as follows:

H2: A negative relationship between ESG risk and firm performance is reinforced by the COVID-19 pandemic.

\section{Data}

\subsection{ESG risk}

This study aimed to examine the interaction between a company's ESG risk and resilience during the COVID-19 pandemic. As a measure of ESG risk, we employed the Sustainalytics ESG Risk Rankings in 2021, obtained through the Bloomberg terminal. Sustainalytics, a member of the United States Morningstar Group, is a leading provider of ESG research, ratings, and data, which have empowered investors worldwide to develop and implement responsible investment strategies for over 25 years. The company has more than 350 analysts with cross-sector expertise in more than 40 industry segments. Moreover, it works with hundreds of leading asset managers and pension funds in 16 offices worldwide, including Japan. Sustainalytics ESG risk ratings are updated through an annual research process by research analysts. The information used in this study comprises public information, including corporate publications and regulatory filings, assessments of management metrics (including a review of ESG corporate scandals), issuer feedback on the ESG report draft, and internal reviews to maintain report quality. ESG risk ratings attempt to understand the degree of exposure to material ESG risks that are inherent in the characteristics of each company's industry and business, and the management of those risks within each company. The rating then provides investors with an assessment of the extent of unmanaged ESG risk in each company, with a rating from 0-100. A high ESG risk rating score indicates a higher number of unmanaged risk factors. However, the ESG risk "ranking" used in this analysis is a reordering of risk in descending order, where higher rankings indicate lower risks.

In addition to the Sustainalytics ESG risk rankings, several other indicators measure a company's ESG performance. However, existing studies have highlighted, for example, that the KLD index is inconsistent and biased because it is based on corporate impressions rather than facts, and that it lacks information on corporate transparency (Griffin and Mahon 1997; Chatterji et al. 2009; Chatterji et al. 2016). Furthermore, Sustainalytics focuses only on ESGrelated risks, rather than ESG performance.

In this analysis, companies with low ESG risk (i.e., those in the top 10\% of the rankings) are defined as "low-ESG-risk firms," whereas companies with high ESG risk, which are at the bottom $10 \%$ of the rankings, are defined as "high-ESG-risk firms," each of which is represented as a dummy variable. Thus, companies with moderate ESG risk can be excluded for clearer observation of the impact of ESG risk.

Furthermore, to avoid mixed and neutral analysis results due to various sizes of companies, only those classified as "large company" under the Japanese Companies Act were targeted. Specifically, companies with a capital of 500 million yen or more or debt of 20 billion yen or more were selected as targets. Financial data, including the amount of capital and debt of the companies, were obtained from the S\&P Capital IQ. The database is a single-source service that provides a wealth of financial data, and analytical and research functions that have been used in many previous studies. These processes left us with a dataset of 7,868 samples of 882 companies for quarterly data and 25,384 samples of 949 firms for monthly data from June 2016 to March 2021.

\subsection{COVID-19}

In this section, we describe the variables related to the COVID-19 outbreak period. In Japan, a cruise ship carrying a person infected with COVID-19 entered the port of Yokohama in February 2020. However, at that time, residents of Japan were not so concerned about the risk of COVID-19 infection, as they perceived it to be a problem of a limited area. It was not until around March 2020 that they started seeing it as their problem. At the time, the rate of deaths and infection were increasing in various parts of Japan, as well as in other countries such as Italy, due to large-scale outbreaks. Thus, in this study, the COVID-19 outbreak period was set to March 2020 and later, with the outbreak period set to 1 and earlier set to 0 as a dummy variable (COVID).

\subsection{Stock returns and firm performance}

This section discusses the variables associated with stock returns and firm performance. First, we used stock returns (Return) as indicators of investors' direct corporate valuation. In addition, we used Tobin's Q (TobinQ), which is the ratio of a company's market value divided by the replacement cost of its assets, as it has been used in many studies as an indicator of corporate value (Buchanan et al. 2018; Albuquerque et al. 2020). Unlike stock returns, which are a more direct response of investors, this index can measure the future valuation or sustainability of a company. While stock returns are monthly data, Tobin's $Q$ is quarterly data.

Indicators of consumer purchasing behavior and financial stability are needed to determine a firm's financial performance. Therefore, both sales-to-assets (SalestoAssets) and ROE were employed in this analysis. The ratio of sales to assets, also known as asset turnover, is an indicator of the efficiency of total assets to generate sales. In this study, it is simply used as a sales level to control asset size. ROE, an index calculated by dividing net income by shareholders'

Page 4/11 
equity and multiplying the value by 100 , is a financial analysis index that represents the profit generated in relation to shareholders' equity. It is considered an indicator of how efficiently a company has managed its equity capital to generate profits; moreover, it is an indicator of a company's financial sustainability. These indicators are quarterly based.

\subsection{Control variables}

Following Albuquerque et al. (2020), Broadstock et al. (2021), and Demers et al. (2021), the control variables in this study are those that measure the size and characteristics of each company. The indicator of firm size is the logarithm of the amount of assets (Size). The cash asset ratio (cash) was calculated by dividing the current value of marketable securities and cash by the company's current liabilities. Moreover, the logarithm of liquidity (Liquidity) was used to assess a company's liquidity or its capacity to meet short-term commitments. The book-to-market ratio compares a company's book value to its market value, which is used to determine its value. Financial leverage (Leverage) is total capital divided by equity capital and indicates the extent of capital generated with the funds invested by shareholders. This is an indicator of profitability in financial analysis. These indices are used on a quarterly and monthly basis, depending on the dependent variables.

In addition, to reflect the characteristics of each industry, we include variables for the industrial category (industry) to which the firm belongs. The industry categories are based on the major categories of the Tokyo Stock Exchange, where the target companies are listed: 1) fisheries, agriculture, and forestry; 2) mining; 3) construction; 4) manufacturing; 5) electric and gas; 6) transportation, information, and communication; 7) commercial; 8) finance and insurance; 9) real estate; and 10) services.

We attempted to add a year dummy variable to control for year-specific effects. However, since it showed a high correlation with the COVID-19 variable, the year dummy variable was removed from the list of variables to avoid multicollinearity.

\section{Methodology}

We applied difference-in-differences regression to determine the impact of the COVID-19 pandemic in the relationship between ESG performance, stock returns, and firm performance. Moreover, we employed difference-in-differences analysis for a quasi-experimental approach that compares the changes in outcomes over time between a treated and untreated group to assess the impact of a particular intervention. Albuquerque et al. (2020) adopted a similar approach, but unlike this study, which focused on stock returns and firm performance, they focused on returns and volatility. Our model is shaped to reflect the different frequencies of data available, depending on the data, namely, monthly or quarterly based.

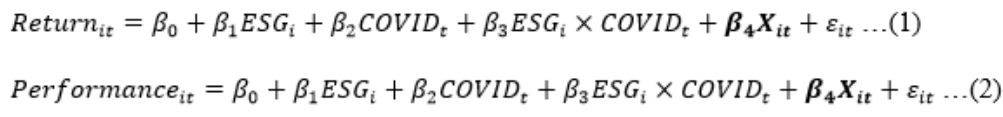

In model (1), for the dependent variable, Return ${ }_{i t}$ stock returns (Return), and Tobin's Q (TobinQ) are used as the monthly data of $\square$ rm i on month t. For model (2), sales to assets (SalestoAssets), and ROE are adopted as the dependent variable, Performance ${ }_{i t}$ as the quarterly data of $\square \mathrm{rm}$ i in quarter t. ESG is represented by two dummy variables, LowESGrisk ${ }_{\mathrm{i}}$ and HighESGrisk $k_{\mathrm{i}}$, which equals 1 for firm i, if its ESG risk rating is in the top quartile in 2020, and 0 otherwise, and 1 for firm i if its ESG risk rating is in the bottom quartile in 2020, and 0 otherwise. COVID-19 $t$ is a dummy variable that has a value of 1 from March 2020-March 2021 and a value of 0 before this time. We include control variables $\left(\mathbf{X}_{i t}\right)$, including the logarithm of the amount of assets (Size), the cash asset ratio (Cash), logarithm of liquidity (Liquidity), book-to-market ratio (BooktoMarket), financial leverage (Leverage), the industrial category (Industry), and a year variable (Year) to control a firm's specific characteristics and reflect the year-specific incidents in the results.

The coefficient of the interaction term $\left(\beta_{3}\right)$ in this equation reflects the causative impact of ESG-related risk on stock returns and firm performance during the COVID-19 pandemic period. Nevertheless, the coefficients for each of the ESG and COVID variables $\beta_{1}$ and $\beta_{2}$ represent the impact of the variables alone, without the influence of both. By conducting this analysis using the difference-in-differences method, we separated the effects of ESG risk and COVID-19 to accurately understand the effect of the external shock of COVID-19 on stock returns and firm performance of companies, with high and low ESG risk. The descriptive statistics and correlations are shown in Tables 1 and 2, confirming that there is no statistical problem. 
Table 1

Descriptive statistics

\begin{tabular}{|c|c|c|c|c|c|}
\hline Variable & Observations & Mean & Std. dev. & Min & Max \\
\hline SalestoAsset & 17,714 & 0.206 & 0.137 & -0.024 & 1.933 \\
\hline TobinQ & 14,967 & 41.058 & 79.642 & 0.012 & $3,135.906$ \\
\hline$R O E$ & 17,552 & 1.837 & 5.258 & -191.420 & 76.878 \\
\hline LowESGrisk & 18,153 & 0.732 & 0.443 & 0 & 1 \\
\hline HighESGrisk & 18,153 & 0.040 & 0.195 & 0 & 1 \\
\hline Leverage & 17,727 & 3.928 & 12.390 & $-1,153.515$ & 239.902 \\
\hline BooktoMarket & 8,583 & 0.001 & 0.020 & -1.667 & 0.187 \\
\hline liquidity & 16,422 & 11.548 & 1.783 & 6.290 & 19.488 \\
\hline \multicolumn{6}{|l|}{ Monthly Data } \\
\hline Return & 62,628 & 0.852 & 15.967 & -221.613 & 252.693 \\
\hline COVID & 64,310 & 0.220 & 0.414 & 0.000 & 1.000 \\
\hline HighESGrisk & 64,310 & 0.034 & 0.181 & 0.000 & 1.000 \\
\hline LowESGrisk & 64,310 & 0.771 & 0.420 & 0.000 & 1.000 \\
\hline Leverage & 63,051 & 3.545 & 14.022 & $-1,153.515$ & 558.652 \\
\hline
\end{tabular}


Table 2

Correlations

\begin{tabular}{|c|c|c|c|c|c|c|c|c|c|c|}
\hline $\begin{array}{l}\text { Quarterly } \\
\text { Data }\end{array}$ & TobinQ & SalestoAsset & $R O E$ & COVID & LowESGrisk & HighESGrisk & Leverage & BooktoMarket & Size & Indust \\
\hline TobinQ & 1 & & & & & & & & & \\
\hline SalestoAsset & 0.0539 & 1 & & & & & & & & \\
\hline ROE & 0.0329 & 0.1357 & 1 & & & & & & & \\
\hline COVID & -0.0318 & -0.0693 & -0.1266 & 1 & & & & & & \\
\hline LowESGrisk & -0.1474 & 0.1816 & 0.0195 & -0.006 & 1 & & & & & \\
\hline HighESGrisk & 0.1269 & 0.0355 & 0.0062 & -0.0026 & -0.289 & 1 & & & & \\
\hline Leverage & 0.0029 & -0.1215 & -0.1432 & 0.0248 & -0.0759 & 0.0057 & 1 & & & \\
\hline BooktoMarket & -0.0357 & 0.1172 & -0.3212 & -0.0218 & 0.0884 & -0.0074 & 0.2209 & 1 & & \\
\hline Size & -0.4384 & -0.2525 & 0.0111 & 0.0223 & -0.2932 & -0.0021 & 0.0453 & -0.1081 & 1 & \\
\hline Industry & 0.1288 & 0.0985 & 0.0174 & -0.0033 & -0.0299 & 0.0622 & 0.1672 & 0.1548 & -0.2577 & 1 \\
\hline Cash & -0.0458 & 0.0655 & -0.0192 & 0.0225 & 0.176 & 0.0273 & -0.1274 & 0.1826 & -0.1248 & 0.09 \\
\hline liquidity & 0.1558 & -0.2572 & -0.019 & 0.0327 & -0.5857 & 0.0666 & 0.28 & -0.2015 & 0.3597 & $-0.004^{\circ}$ \\
\hline Monthly Data & Return & COVID & HighESGrisk & LowESGrisk & Leverage & BooktoMarket & Size & Industry & & \\
\hline Return & 1 & & & & & & & & & \\
\hline COVID & 0.0202 & 1 & & & & & & & & \\
\hline HighESGrisk & -0.005 & 0.0006 & 1 & & & & & & & \\
\hline LowESGrisk & 0.0069 & -0.0079 & -0.3383 & 1 & & & & & & \\
\hline Leverage & 0.0033 & 0.0211 & 0.025 & -0.0388 & 1 & & & & & \\
\hline BooktoMarket & -0.0098 & 0.0093 & 0.0015 & -0.0031 & 0.628 & 1 & & & & \\
\hline Size & 0.0084 & 0.033 & 0.0769 & -0.3893 & 0.0628 & 0.0136 & 1 & & & \\
\hline Industry & 0.0034 & -0.0075 & 0.0878 & -0.0212 & 0.1244 & 0.0127 & -0.1508 & 1 & & \\
\hline
\end{tabular}

\section{Empirical Results}

We used quarterly and daily data and an event dummy, COVID-19 ${ }_{t}$ to perform a difference-in-differences analysis, with the aim of identifying an association between stock returns and firm performance of companies with ESG risk and the COVID-19 pandemic. The results are shown in Table 3. 
Table 3

Difference-in-Differences analysis results

\begin{tabular}{|c|c|c|c|c|c|c|c|c|}
\hline Variable & Retum & TobinQ & SalestoAsset & $R O E$ & Return & TobinQ & SalestoAsset & $R O E$ \\
\hline \multirow[t]{2}{*}{ COVID } & $0.637^{\star \star \star}$ & $-2.981 \star \star$ & 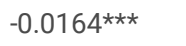 & $-1.607 * \star \star$ & $0.901^{*}$ & $-10.18^{\star \star \star}$ & 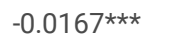 & $-1.930 \star \star \star *$ \\
\hline & $(0.241)$ & $(1.290)$ & $(0.000973)$ & $(0.127)$ & $(0.460)$ & $(2.406)$ & $(0.00182)$ & $(0.242)$ \\
\hline \multirow[t]{2}{*}{ COVID $\times$ HighESGrisk } & 1.096 & $-46.63^{\star * *}$ & $-0.0209 * * *$ & $-1.590 \star \star$ & & & & \\
\hline & $(1.250)$ & $(7.381)$ & $(0.00530)$ & $(0.709)$ & & & & \\
\hline \multirow[t]{2}{*}{ COVID $\times$ LowESGrisk } & & & & & -0.307 & $8.630 * \star \star$ & -0.000737 & 0.342 \\
\hline & & & & & $(0.536)$ & $(2.813)$ & $(0.00211)$ & $(0.281)$ \\
\hline \multirow[t]{2}{*}{ HighESGrisk } & -0.940 & $72.62^{\star \star \star}$ & -0.00722 & -0.117 & & & & \\
\hline & $(0.601)$ & $(12.77)$ & $(0.0232)$ & $(0.888)$ & & & & \\
\hline \multirow[t]{2}{*}{ LowESGrisk } & & & & & $0.580 * \star$ & $-43.05^{\star \star \star}$ & $0.0196^{*}$ & $1.132^{\star \star}$ \\
\hline & & & & & $(0.269)$ & $(6.191)$ & $(0.0106)$ & $(0.440)$ \\
\hline \multirow[t]{2}{*}{ Size } & -0.0217 & $-23.73^{\star \star *}$ & $-0.0205^{\star \star \star}$ & 0.105 & 0.00891 & $-24.55^{\star \star \star}$ & $-0.0204^{\star \star \star}$ & $0.127 *$ \\
\hline & $(0.0469)$ & $(1.082)$ & $(0.00185)$ & $(0.0730)$ & $(0.0495)$ & $(1.083)$ & $(0.00185)$ & $(0.0734)$ \\
\hline \multirow[t]{2}{*}{ Leverage } & $0.0670 * \star \star$ & 0.0536 & $-0.00155^{\star \star \star}$ & $-0.288^{* \star \star}$ & $0.0679 * \star \star$ & 0.194 & $-0.00157^{\star \star \star}$ & $-0.293^{\star \star \star}$ \\
\hline & $(0.0146)$ & $(0.259)$ & $(0.000243)$ & $(0.0205)$ & $(0.0146)$ & $(0.259)$ & $(0.000244)$ & $(0.0206)$ \\
\hline \multirow[t]{2}{*}{ BooktoMarket } & 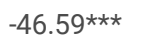 & -34.23 & $1.137 \star \star \star$ & $-643.1^{\star \star \star}$ & $-47.35^{\star \star \star}$ & -131.5 & $1.152^{\star \star \star}$ & $-638.7 * \star \star *$ \\
\hline & (10.96) & $(180.1)$ & $(0.169)$ & $(23.06)$ & $(10.97)$ & (180.6) & $(0.169)$ & (23.12) \\
\hline \multirow[t]{2}{*}{ Industry } & -0.0179 & -0.129 & $0.00592^{\star \star \star}$ & $0.369 \star \star \star$ & -0.0147 & -0.342 & $0.00592^{\star \star \star}$ & $0.380 * \star \star$ \\
\hline & $(0.0544)$ & $(1.243)$ & $(0.00227)$ & $(0.0852)$ & $(0.0544)$ & $(1.238)$ & $(0.00226)$ & $(0.0851)$ \\
\hline \multirow[t]{2}{*}{ Cash } & & -0.150 & $-0.0901^{\star \star \star}$ & $1.888^{\star \star}$ & & 3.938 & $-0.0913^{\star \star \star}$ & $1.924^{\star \star}$ \\
\hline & & (11.81) & $(0.00978)$ & $(0.844)$ & & (11.79) & $(0.00984)$ & $(0.842)$ \\
\hline \multirow[t]{2}{*}{ Liquidity } & & $16.09 * * \star$ & $-0.00439 * \star$ & 0.101 & & $11.28^{\star \star \star}$ & -0.00284 & $0.264^{\star \star}$ \\
\hline & & $(1.430)$ & $(0.00215)$ & $(0.102)$ & & (1.639) & $(0.00232)$ & $(0.118)$ \\
\hline \multirow[t]{2}{*}{ Constant } & 0.330 & $103.5^{\star \star \star}$ & $0.485^{\star \star *}$ & -0.657 & -0.468 & $201.8^{\star \star \star *}$ & $0.452^{\star \star *}$ & $-3.665^{\star \star}$ \\
\hline & $(0.629)$ & (18.68) & $(0.0262)$ & $(1.316)$ & $(0.733)$ & $(24.17)$ & $(0.0320)$ & $(1.725)$ \\
\hline Observations & 25,097 & 7,020 & 7,868 & 7,823 & 25,097 & 7,020 & 7,868 & 7,823 \\
\hline Prob > chi2 & $1.86 \mathrm{e}-05$ & 0 & 0 & 0 & $6.61 \mathrm{e}-06$ & 0 & 0 & 0 \\
\hline \multicolumn{9}{|l|}{ Standard errors in parentheses } \\
\hline \multicolumn{9}{|l|}{${ }^{* * *} p<0.01, * * p<0.05, * p<0.1$} \\
\hline ROE: & montol & & ance & & & & & \\
\hline
\end{tabular}

\subsection{Impact of ESG risk on stock returns}

First, we examined the relationship between ESG risk and stock returns before and after COVID-19. This study used stock returns (Return) and Tobin's Q (TobinQ) as dependent variables. For stock returns (Return), we first found that the post-COVID-19 variable (COVID) had a significantly positive impact on stock returns with a coefficient of $0.637 \%$ with high ESG risk and $0.901 \%$ with low ESG risk, indicating that stock prices increased after COVID-19, regardless of ESG risk. For the intersection variable of ESG risk and post-COVID-19 (ESG×COVID), no significant results were obtained.

In terms of Tobin's Q, which is an indicator of long-term corporate value, the post-COVID-19 variable (COVID) had a significantly negative effect on Tobin's Q, with a coefficient of $-2.981 \%$ with high ESG risk and $-10.18 \%$ with low ESG risk, suggesting that Tobin's Q decreased independent of ESG risk after COVID-19. The cross term of high ESG risk and COVID-19 showed a statistically significant result, with a coefficient of $-46.63 \%$. This result indicates that, following the COVID-19 pandemic, the greater the ESG risk, the lower the Tobin's Q. Moreover, the cross term between low ESG risk and COVID-19 was statistically significant, with a coefficient of $8.63 \%$. In other words, in the aftermath of COVID-19, the lower the ESG risk, the greater the Tobin's Q. These findings show that the impact of ESG risk on long-term firm valuation shifted in the years after COVID-19.

As for control variables, leverage (Leverage) had a positive impact, whereas book-to-market ratio (BooktoMarket) had a negative impact on stock returns. Moreover, the logarithm of the amount of assets (Size) had a positive impact, whereas the logarithm of liquidity (Liquidity) had a negative impact on Tobin's Q. 
Given the aforementioned results, we can see that, although the COVID-19 event itself resulted in lowering long-term corporate value and Tobin's Q, high ESG risk further reduced the value, while low ESG risk increased the value. This result supports Hypothesis 1.

\subsection{Impact of ESG risk on firm performance}

In this section, we investigated the connection between ESG risk and firm performance with COVID-19. First, we used sales to assets (SalestoAssets) to determine firm performance in terms of income. Table 3 show that, for the post-Covid-19 impact alone, which excludes the influence of ESG risk, SalestoAssets is significantly negative with a coefficient of $-0.0164 \%$ for high ESG risk and $-0.0167 \%$ for low ESG risk, showing that sales fell after the Covid- 19 pandemic, regardless of ESG risk. For the cross term, high ESG risk and Covid-19 are statistically significant with a coefficient of $-0.0209 \%$. That is, after the Covid-19 pandemic, the higher the ESG risk, the lower the sales to assets. On the other hand, we observed no significant relationship between companies with low ESG risk companies. This result shows a change in the magnitude of ESG risk, especially the impact of high ESG risk on sales, before and after the Covid-19 pandemic.

Next, we examined the relationship between ESG risk and a firm's financial robustness in the Covid-19 environment. We used ROE (ROE) to measure a company's financial condition. For the post-Covid-19 effect alone, ROE is significantly negative, with a coefficient of $-1.607 \%$ for high ESG risk and $-1.930 \%$ for low ESG risk, indicating that financial efficiency decreased post-Covid-19, regardless of ESG risk. For the cross term between high ESG risk and Covid-19, the result is statistically significant with a coefficient of $-1.590 \%$. This finding shows that after the Covid-19 pandemic, the higher the ESG risk, the lower the ROE. However, we found no significant connection between businesses with low ESG risk, Covid-19, and ROE. These results indicate that in the years after Covid-19, the effect of ESG risk on financial robustness changed, especially for high ESG risk companies.

For the control variables, leverage (Leverage), book-to-market ratio (BooktoMarket), and the industrial category (Industry) have a positive impact, while assets (Size), cash-to-assets ratio (Cash), and logarithm of liquidity (Liquidity) have a negative impact on sales to assets. The industrial category (Industry) and the cash-to-assets ratio (Cash) have a positive impact on ROE, while leverage (Leverage) and the book-to-market ratio (BooktoMarket) have a negative impact. Based on the findings for sales to assets and ROE, we may conclude that in the post-Covid-19 society, ESG risk, particularly high ESG risk, will affect a firm's financial performance. This lends credence to Hypothesis 2.

\section{Discussion}

In this study, we used a difference-in-differences analysis to determine the relationship between stock returns and firm performance of businesses facing ESG risk and the COVID-19 pandemic. By adding the intersection term of the ESG risk index and the post-COVID-19 dummy variable, the before-after effect can be captured accurately. This study found that the negative relationship between corporate ESG risk and stock returns or firm performance was reinforced after COVID-19. This finding offers significant contributions to the field of ESG research and the literature on financial risk.

First, in the year after COVID-19, the effect of ESG risk on long-term company value (i.e., Tobin's Q) changed. This result is in accordance with prior studies, which state that investors are more risk averse in the presence of external shocks (Guiso et al. 2018; Ortmann et al. 2020; Wang and Young 2020; Rubbaniy et al. 2021), as well as those that claim that having a high ESG rating is considered an indicator of a stable and reliable firm (Jo and Na 2012; Durand et al. 2019; Saxton et al. 2019). This finding indicates that investors in the Japanese market are more inclined to avoid firms with high ESG risk after their exposure to COVID-19. A survey on ESG investment of approximately 2,000 Japanese people conducted by International (2021) in January 2021 found that more than $30 \%$ wanted to invest or save for ESG to help build a better world, whereas one in four said they expected companies that do not emphasize ESG to decline.

Next, we found that corporate ESG risk is negatively related to firm performance, indexed by the sales-to-asset ratio and ROE, following the COVID-19 pandemic. We discovered that greater ESG risk lowered sales-to-asset ratio. This demonstrates that the impact of ESG risk changed owing to the COVID-19 pandemic, particularly the effect of high ESG risk on sales. In other words, companies with high ESG risk are more likely to lose customers because of external socioeconomic shocks, compared with those with lower ESG risk. This result is consistent with the theories of prior studies that state that people change their economic behavior when they are worried or irritated, and that they become more prosocial when they experience an external shock (Loewenstein 2000; Sheth et al. 2011; Gualtieri et al. 2019). This outcome can be interpreted as follows: after experiencing COVID-19, Japanese customers are more likely to consider social and environmental issues and refrain from purchasing from companies with high ESG risk. This finding is supported by the fact that customers are losing trust in companies after COVID-19; thus, they are looking for companies that bring them more safety, according to the Consumer Pulse Survey (MayAugust 2020) conducted by International (2020) among consumers in 12 countries and regions, including Japan. This study also confirms that, after the COVID-19 outbreak, the higher the ESG risk, the lower the ROE. Thus, from the results, we can infer that in a post-COVID-19 society, a higher ESG risk will have a greater effect on a firm's financial robustness, compared with the pre-COVID-19 period. This finding is compatible with prior studies, which state that better corporate governance reduces the financial risk of external shocks (Nguyen et al. 2015; Jebran and Chen 2021). In other words, companies with weak corporate governance are more vulnerable to external shocks. Thus, in post-COVID-19 Japan, companies with high ESG risk are more exposed to financial risks. According to a survey by Tokyo Shoko Research (2020), the ratio of companies that experienced bankruptcy in 2020 had a high interest-bearing debt component of $64 \%$. Moreover, the rate of companies unable to cover interest payments with operating income reached $35.2 \%$, which is about six times that of surviving companies, indicating that they were heavily burdened with excessive debt, repaying loans, and paying interest.

This study demonstrates the change in COVID-19's influence on the connection between bad ESG performance, stock returns, and firm performance by targeting "ESG risk." Additionally, by using the most current data available, we were able to perform the study after COVID-19, for which there are still very few studies.

Another contribution of this study is that it focuses on the Japanese market, which lacks substantial research in this field. Along with the broader theory, viewing the data with respect to specific features of the Japanese market added an element of uniqueness to the study. The findings of this study will be 
significant not only for Japan, but also for other nations in a comparable stage of ESG implementation, including East Asian countries.

\section{Conclusions}

This study evaluated the impact of ESG performance on stock returns and company performance by utilizing the interaction effect of COVID-19, with a particular emphasis on companies with poor ESG performance. With 7,868 samples of 882 businesses from June 2016-March 2021, we used difference-indifferences regression to assess changes in these indicators, following COVID-19. Our findings show that after COVID-19, there is a stronger negative connection between ESG risk, stock returns, and business success. We discovered that although there are no substantial results regarding stock returns, the impact of ESG risk on the value of long-term companies was altered in the years after the COVID-19 pandemic. We also observed that the effect of ESG risk on sales and ROE increased after the COVID-19 outbreak.

Apart from these contributions to the body of research on ESG risk, stock returns, and firm performance in businesses, the findings of this study have implications for business ethics and offer practical advice to managers. Our study suggests that managers should put a greater focus on ESG initiatives in the post-COVID-19 environment. This enables companies to keep customers and investors connected and financially stable, even in the face of unexpected external shocks. Referencing to Sustainalytics. ${ }^{1}$ corporations should focus on corporate governance, access to basic services such as healthcare services, bribery and corruption, general professional ethics such as taxation and accounting, community relations, data privacy and security emissions, effluents and waste, carbon, environmental and social impact of products and services, human rights, management of human resources, land use and biodiversity, occupational health and safety, ESG integration with financials, product governance, financial stability and the management of related risks, efficient and effective resource use. In other words, strengths in these areas can lower ESG-related risks. Moreover, in this study we observed a wide range of ESG-related issues that require company-wide planning and measures. In addition, more proactive disclosure of information on a company's ESG activities will be an important strategy, especially for customers and investors who may be affected by the signaling effects of ESG ratings.

Despite these contributions and implications for management, our study had some limitations. First, the limited number of data samples after the COVID-19 pandemic was a handicap. To observe the world after COVID-19, we tried to obtain the most recent data possible; however, the COVID-19 outbreak began in late 2019 or early 2020; therefore, the period of data collection after COVID-19 was just under a year and a half. However, we have compensated for this shortcoming by setting the number of target companies to 882 companies with 7,868 samples for quarterly data and 949 firms with 25,384 samples for monthly data, which is sufficiently large. Second, this study focused on Japanese companies, and comparisons with other countries were simple. While this study listed the characteristics of the Japanese market based on many prior studies, it would be better to make comparisons with other countries such as Europe, the United States, and Asia for deeper insights. Further research is required to gauge the relationship between corporate ESG risk and resilience more accurately.

\section{Declarations}

\section{Acknowledgements}

We would like to thank Editage www.editage.com) for English language editing.

\section{Competing interests}

The author has no competing interests to declare that are relevant to the content of this article.

\section{Funding}

The study was funded by Grants-in-Aid for Scientific Research (JSPS KAKENHI) from the Government of Japan (Grant Numbers: 20K22104 and 21K13388).

\section{References}

1. Adams CA, Abhayawansa S (2021) Connecting the COVID-19 pandemic, environmental, social and governance (ESG) investing and calls for "harmonisation" of sustainability reporting.Crit Perspect Acc102309

2. Albuquerque R, Koskinen Y, Yang S, Zhang C (2020) Resiliency of environmental and social stocks: an analysis of the exogenous COVID-19 market crash. Rev Corp Fin Stud 9:593-621

3. Albuquerque R, Koskinen Y, Zhang C (2019) Corporate social responsibility and firm risk: theory and empirical evidence. Manag Sci 65:4451-4469

4. Bae K-H, El Ghoul S, Gong Z(J), Guedhami O (2021) Does CSR matter in times of crisis? Evidence from the COVID-19 pandemic. J Corp Fin 67:101876

5. Broadstock DC, Chan K, Cheng LTW, Wang X (2021) The role of ESG performance during times of financial crisis: evidence from COVID-19 in China. Finance Res Lett 38:101716

6. Buchanan B, Cao CX, Chen C (2018) Corporate social responsibility, firm value, and influential institutional ownership. J Corp Fin 52:73-95

7. Carroll AB, Shabana KM (2010) The business case for corporate social responsibility: a review of concepts, research and practice. Int J Manag Rev $12: 85-105$

8. Chatterji AK, Durand R, Levine DI, Touboul S (2016) Do ratings of firms converge? Implications for managers, investors and strategy researchers. Strateg Manag J 37:1597-1614

9. Chatterji AK, Levine DI, Toffel MW (2009) How well do social ratings actually measure corporate social responsibility? J Econ Manag Strategy 18:125169

Page $10 / 11$ 
10. KPMG international (2020) The consumer pulse survey (May-August 2020). https://home.kpmg/xx/en/home/insights/2020/11/consumers-and-the-newreality.html, Accessed 1 Aug, 2021 KPMG International

11. Demers E, Hendrikse J, Joos P, Lev B (2021) ESG did not immunize stocks during the COVID-19 crisis, but investments in intangible assets did. J Bus Finance Account 48:433-462

12. Díaz V, Ibrushi D, Zhao J (2021) Reconsidering systematic factors during the COVID-19 pandemic - the rising importance of ESG. Fin Res Lett $38: 101870$

13. Durand R, Paugam L, Stolowy H (2019) Do investors actually value sustainability indices? Replication, development, and new evidence on CSR visibility. Strateg Manag J 40:1471-1490

14. Engelhardt N, Ekkenga J, Posch P (2021) ESG Ratings and stock performance during the COVID-19 crisis. Sustainability 13:7133

15. Folger-Laronde Z, Pashang S, Feor L, ElAlfy A (2020) ESG ratings and financial performance of exchange-traded funds during the COVID-19 pandemic.J Sustain Fin Invest1-7

16. Friede G, Busch T, Bassen A (2015) ESG and financial performance: aggregated evidence from more than 2000 empirical studies. J Sustain Fin Invest 5:210-233

17. Galbreath J (2013) ESG in focus: the Australian evidence. J Bus Ethics 118:529-541

18. Global Sustainable Investment Alliance (2018) Global Sustainable 2018 investment review. http://www.gsi-alliance.org/trends-report-2018/accessed Accessed 1 Aug, 2021 Global Sustainable Investment Alliance

19. Griffin JJ, Mahon JF (1997) The corporate social performance and corporate financial performance debate. Bus Soc 36:5-31

20. Gualtieri G, Nicolini M, Sabatini F (2019) Repeated shocks and preferences for redistribution. J Econ Behav Organ 167:53-71

21. Guiso L, Sapienza P, Zingales L (2018) Time varying risk aversion. J Financ Econ 128:403-421

22. He H, Harris L (2020) The impact of COVID-19 pandemic on corporate social responsibility and marketing philosophy. J Bus Res 116:176-182

23. Heaton J, Lucas D (2000) Portfolio choice and asset prices: the importance of entrepreneurial risk. J Fin 55:1163-1198

24. Hoepner AGF, Oikonomou I, Sautner Z et al (2016) ESG shareholder engagement and downside risk. SSRN Electron J doi. 10.2139/ssrn.2874252

25. International F (2021) Survey on ESG investment. https://www.fidelity.co.jp/articles/press-releases/20210622-1-1624258723598 Accessed 1 Aug, 2021

26. Jebran K, Chen S (2021) Can we learn lessons from the past? COVID-19 crisis and corporate governance responses. Int J Fin Econ. doi: $10.1002 / i j f e .2428$

27. Jo H, Na H (2012) Does CSR reduce firm risk? Evidence from controversial industry sectors. J Bus Ethics 110:441-456

28. Kanamura T (2021) Risk mitigation and return resilience for high yield bond ETFs with ESG components. Fin Res Lett 41:101866

29. Kuhnen CM, Knutson B (2011) The influence of affect on beliefs, preferences, and financial decisions. J Financ Quant Anal 46:605-626

30. Lai A, Melloni G, Stacchezzini R (2016) Corporate sustainable development: is "integrated reporting" a legitimation strategy? Bus Strategy Environ 25:165-177

31. Loewenstein G (2000) Emotions in economic theory and economic behavior. Am Econ Rev 90:426-432

32. Euro RSCGworldwide (2010) The new consumer in the era of mindful spending. Prosumer Report, 8 New York

33. Nguyen T, Nguyen HGL, Yin X (2015) Corporate governance and corporate financing and investment during the 2007-2008 financial crisis. Financ Manag 44:115-146

34. Ortas E, Moneva JM, Burritt R, Tingey-Holyoak J (2014) Does sustainability investment provide adaptive resilience to ethical investors? Evidence from Spain. J Bus Ethics 124:297-309

35. Ortmann R, Pelster M, Wengerek ST (2020) COVID-19 and investor behavior. Finance Res Lett 37:101717

36. Revelli C, Viviani J-L (2015) Financial performance of socially responsible investing (SRI): what have we learned? A meta-analysis. Bus Ethics Eur Rev 24:158-185

37. Rubbaniy G, Khalid AA, Ali S, Naveed M (2021) Are ESG stocks safe-haven during COVID-19? SSRN Electron J doi. 10.2139/ssrn.3779430

38. Saxton GD, Gomez L, Ngoh Z et al (2019) Do CSR messages resonate? Examining public reactions to firms' CSR efforts on social media. J Bus Ethics 155:359-377

39. Shanaev S, Ghimire B (2021) When ESG meets AAA: the effect of ESG rating changes on stock returns.Fin Res Lett.102302

40. Sheth JN, Sethia NK, Srinivas S (2011) Mindful consumption: a customer-centric approach to sustainability. J Acad Mark Sci 39:21-39

41. Shoko T (2020) Research The study on financial data analysis of bankrupt companies. Tokyo Shoko research. https://www.tsrnet.co.jp/news/analysis/20210330_01.html, Accessed 1 Aug, 2021

42. Sison AJG, Ferrero I, Guitián G (2019) Characterizing virtues in finance. J Bus Ethics 155:995-1007

43. Suchman MC (1995) Managing legitimacy: strategic and institutional approaches. Acad Manag Rev 20:571-610

44. Teikoku databank (2021) Survey on trends in COVID-19-related bankruptcies. Teikoku databank. https://www.tdb.co.jp/tosan/covid19/pdf/tosan.pdf, Accessed 1 Aug, 2021

45. Takahashi H, Yamada K (2021) When the Japanese stock market meets COVID-19: impact of ownership, China and US exposure, and ESG channels. Int Rev Financ Anal 74:101670

46. Voinea L, Filip A (2011) Analyzing the main changes in new consumer buying behavior during economic crisis. Int J Econ Pract Theor 1:14-19

47. Wang AY, Young M (2020) Terrorist attacks and investor risk preference: evidence from mutual fund flows. J Financ Econ 137:491-514

48. Yoo S, Keeley AR, Managi S (2021) Does sustainability activities performance matter during financial crises? Investig Case COVID 19.Energy Policy:155. 112330

Page 11/11 